\title{
Structured Mathematical Modeling of Industrial Boiler
}

\author{
Abdullah Nur Aziz ${ }^{1}$, Yul Yunazwin Nazaruddin², \\ Parsaulian Siregar ${ }^{2}$ \& Yazid Bindar ${ }^{3}$ \\ ${ }^{1}$ Electronics and Instrumentations Laboratory, Physics Study Program, \\ Faculty of Science and Engineering, Jenderal Soedirman University \\ Jalan Dr. Soeparno 61, Purwokerto 53123, Indonesia \\ ${ }^{2}$ Instrumentation and Control Research Group, Engineering Physics Program Study, \\ Faculty of Industrial Technology, Bandung Institute of Technology, \\ Jalan Ganesha 10, Bandung 40132, Indonesia \\ ${ }^{3}$ Energy and Processing System of Chemical Engineering, Faculty of Industrial \\ Technology, Bandung Institute of Technology, \\ Jalan Ganesha 10, Bandung 40132, Indonesia \\ Email: abd.nur.aziz@unsoed.ac.id
}

\begin{abstract}
As a major utility system in industry, boilers consume a large portion of the total energy and costs. Significant reduction of boiler cost operation can be gained through improvements in efficiency. In accomplishing such a goal, an adequate dynamic model that comprehensively reflects boiler characteristics is required. This paper outlines the idea of developing a mathematical model of a water-tube industrial boiler based on first principles guided by the bond graph method in its derivation. The model describes the temperature dynamics of the boiler subsystems such as economizer, steam drum, desuperheater, and superheater. The mathematical model was examined using industrial boiler performance test data. It can be used to build a boiler simulator or help operators run a boiler effectively.
\end{abstract}

Keywords: dynamic model; economizer; industrial boiler; physical model; steam drum; superheater.

\section{$1 \quad$ Introduction}

Modeling and simulation of boiler systems has been an interesting subject of investigation for many years. Generally, boiler models can be categorized into three groups, i.e. complex models, moderately complex models, and simpler models. The complex models involve enormous nonlinear differential equations as well as algebraic equations, variables, and parameters. Descriptive accounts of such complex models can be found in e.g. Marwa, et al. [1]. In design and implementation, however, the complexities need to be reduced and many variables should be excluded, as outlined in e.g. Astrom and Bell [2], Cheres [3], and de Mello [4].

Received August $23^{\text {rd }}, 2011,1^{\text {st }}$ Revision February $16^{\text {th }}, 2012,2^{\text {nd }}$ Revision October $18^{\text {th }}, 2012,3^{\text {rd }}$ Revision December 24 $4^{\text {th }}, 2012,4^{\text {th }}$ Revision February 28 $8^{\text {th }}, 2014$, Accepted for publication March $1^{\text {st }}, 2014$.

Copyright $\odot 2014$ Published by ITB Journal Publisher, ISSN: 2337-5779, DOI: 10.5614/j.eng.technol.sci.2014.46.1.7 
The boiler model can be either derived from fundamental laws of physics or based on measured data from real plant operation. The first approach considers mass, momentum, and energy conservation as well as the laws of heat and mass transfer. The second approach utilizes system identification techniques to develop black-box models that describe the system ina particular operating condition. A working example of the second approach can be found in Nazaruddin, et al. [5,6].

In recent years, the bond graph as a graphical model representation has been widely accepted as a method to describe multi-energy systems. It has been proven to help scientists and engineers to better and deeper understand the underlying physical interactions in multi-energy platforms. Therefore, a proper model that represents a system involving energy can be extracted in a structured manner (Marwa, et al. [1] and Boroutzky [7]).

This article outlines the idea of developing mathematical models with multiple ordinary differential and algebraic equations guided by the bond graph methodology in order to simulate the thermal behavior of water-tube boilers. Some simulations use step change at the equation's input in order to demonstrate the model's quality. The responses of mathematical models can also be validated through steady-state performance test data of real boilers.

The rest of the paper will be organized as follows. Section 2 briefly describes the steam generation process and its subsystems. Bond graph models and their state equation will be discussed in Section 3. Section 4 gives results and discussion of the performance examination through simulation of the model developed in this research and, finally, Section 5 gives concluding remarks.

\section{System Description}

The investigation was conducted on one of the water-tube boilers that operate in an oil refinery plant. There are four boilers with 110 ton/hrs capacities each. They produce steam, which is channelled into a common header at a specific pressure and temperature. The pressure and temperature are maintained at 60 $\mathrm{kg} / \mathrm{cm}^{2}$ and $460^{\circ} \mathrm{C}$ respectively, regardless of load conditions. These tasks are performed by combustion, temperature, and a drum level control system.

Heat is supplied by a furnace, which is equipped with three burners, and reaches the boiler bank tubes by radiation and a convection mechanism. Water is boiled in the tubes and converted into steam at the upper end of the tubes. The hot steam product is further heated by passing it through superheaters. Figure 1 shows the schematic diagram of the boiler cross section under investigation. 
The superheated steam from the outlet header goes into the main steam header, which is connected to generators, turbine, and other processors in the refinery plant.

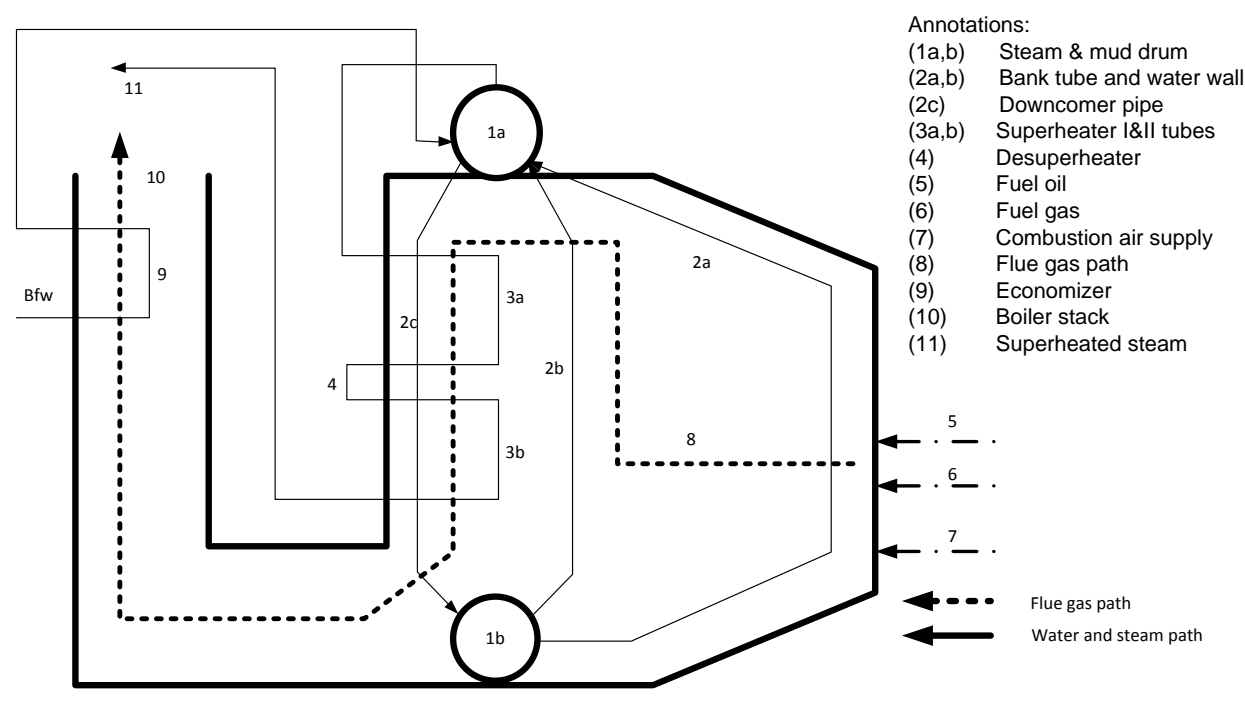

Figure 1 Boiler cross section.

\section{$3 \quad$ Modeling Methodology}

The modeling of the main components of the boiler system, such as economizer, steam drum, desuperheater and superheaters, was performed using bond graph methodology. The method is capable of modeling multi-energy systems in a structured way. It uses two kinds of variables, i.e. flow and effort, where their multiplication has units of power. It is mentioned in Medjaher, et al. [8] that complexity of bond graph modeling phases may arise in the modeling of open thermodynamic systems. In order to remove the complexities, the pseudobond graph method was selected as the model representation. The term pseudo implies that multiplication of the flow and effort variables does not result in units of power.

The typical boiler subsystems and variables involved are represented bythe Input-Process-Output diagram as shown in Figure 2. The bond graph model of the convection heat transfer mechanism is adapted from the work of Medjaher [8] for vertical U-tube condenser modeling. It is expressed as thermal and hydraulic coupling elements, as shown in Figure 3. It is also used to model the radiation mechanism in the heat transfer processes. 


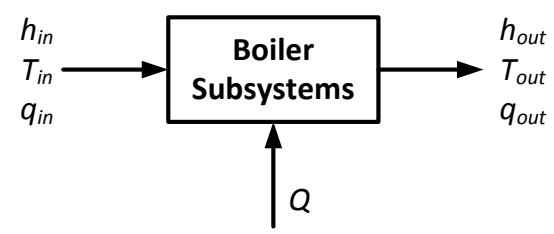

Figure 2 Input-process-output diagram and their relevant variables.

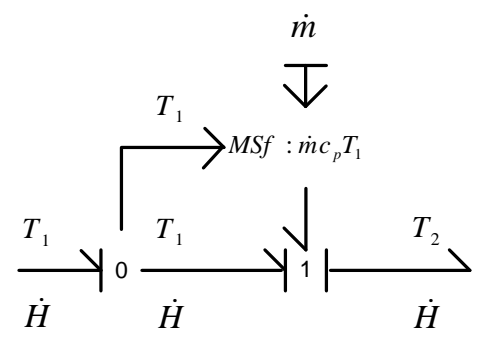

Figure 3 Coupling thermal and hydraulic systems.

\subsection{Word Bond Graph Model}

On a technological level, industrial boilers can be modeled as interconnected subsystems, the interrelations of which illustrate the power flow among them. Such a model is called the word bond graph. The word bond graph model for an industrial boiler is shown in Figure 4.

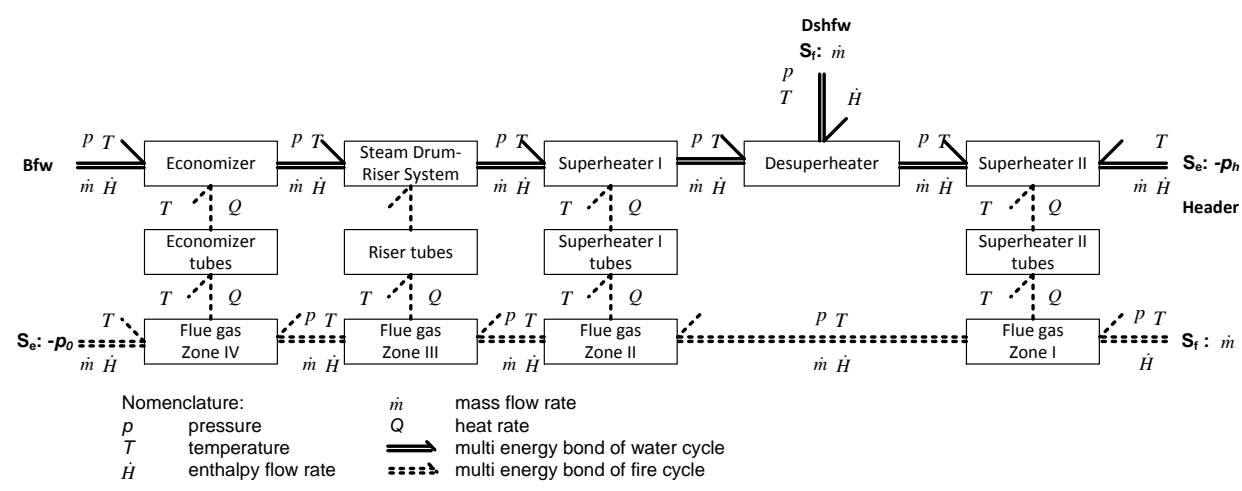

Figure 4 Word bond graph of boiler system.

The boxes in the figure represent the boiler subsystems under investigation, while the half arrow lines represent the power flow over each subsystem. The word bond graph model describes the process of steam generation in the water tube boiler, i.e. the water-cycle and the fire-cycle. 
Heat from the higher enthalpy fluid (flue gas) is transferred to the lower one (water in liquid and/or steam phase), as depicted in Figure 4. The main heat transfer mechanisms in the heat exchangers are found to be radiation and convection. The identified energy sources in the word bond graph are hydraulic and thermal energy of air supply for combustion, boiler feed water system, fuel oil and fuel gas supply, and desuperheater feed water supply. The movements of materials like flue gas and water/steam are naturally driven by the gradient of upstream and downstream pressure of the subsystem or zone.

The double half arrow symbol in the figure represents a multi-energy bond. It consists of a hydraulic and a thermal energy system. Pressure $(p)$ and temperature $(T)$ are set as effort variables, and mass flow rate $(\dot{m})$ and enthalpy flow $(\dot{H})$ are assigned as flow variables. The following paragraphs will elaborate the word bond graph model for each subsystem.

\subsubsection{Word Bond Graph of Economizer Subsystem}

An ideal physical model of the economizer subsystem is shown in Figure 5. The corresponding word bond graph for the economizer with adjacent subsystems is depicted in Figure 6. The heat contained in the flue gas is transferred into the boiler feed water through pipes by a convection mechanism. The flow of feed water and flue gas are driven by the difference between the upstream and downstream pressure of each subsystem.

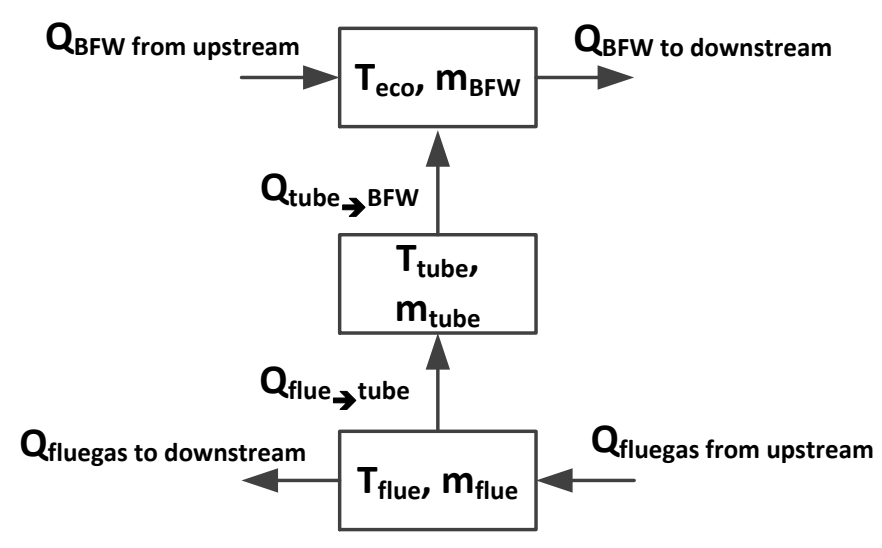

Figure 5 Ideal physical model of economizer subsystem.

The mathematical model of the economizer can be expressed as follows:

$$
y_{\text {out }}=f(x, u, d)
$$


$\boldsymbol{y}_{\text {out }}$ is the temperature outlet, $\boldsymbol{x}^{\prime} \boldsymbol{s}$ are the temperature outlet, economizer tube, and flue gas, $\boldsymbol{u}^{\prime} \boldsymbol{s}$ are: temperature and pressure of boiler feed water, and $\boldsymbol{d}^{\prime} \boldsymbol{s}$ are temperature and pressure of surrounding air.

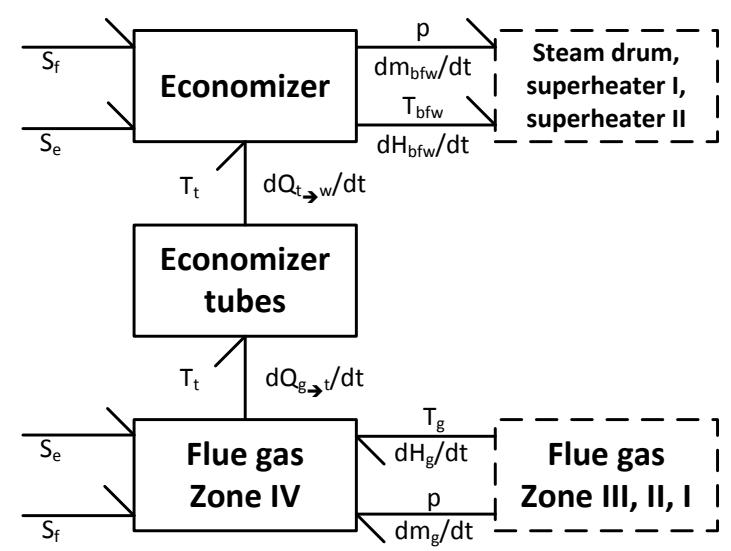

Figure 6 Details of word bond graph for economizer subsystem.

\subsubsection{Word Bond Graph of Steam-Drum-Riser Loop Subsystem}

The ideal physical model of the steam-drum-riser loop subsystem is depicted in Figure 7, while its word bond graph model is shown in Figure 8. Steam drum, down comer pipes, and riser pipes are treated as a lump subsystem. The heat of the flue gasin the $3^{\text {rd }}$ zone is used to raise the water up along vertical riser pipes.

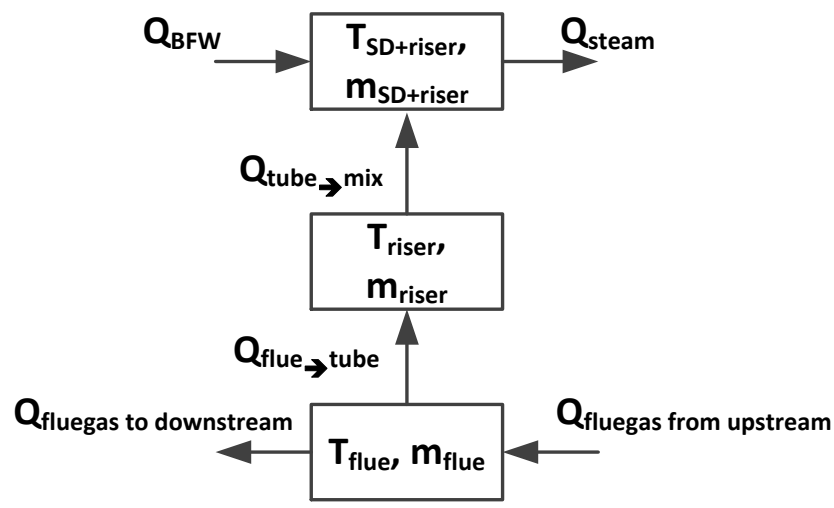

Figure 7 Ideal physical model of steam-drum-riser loop. 


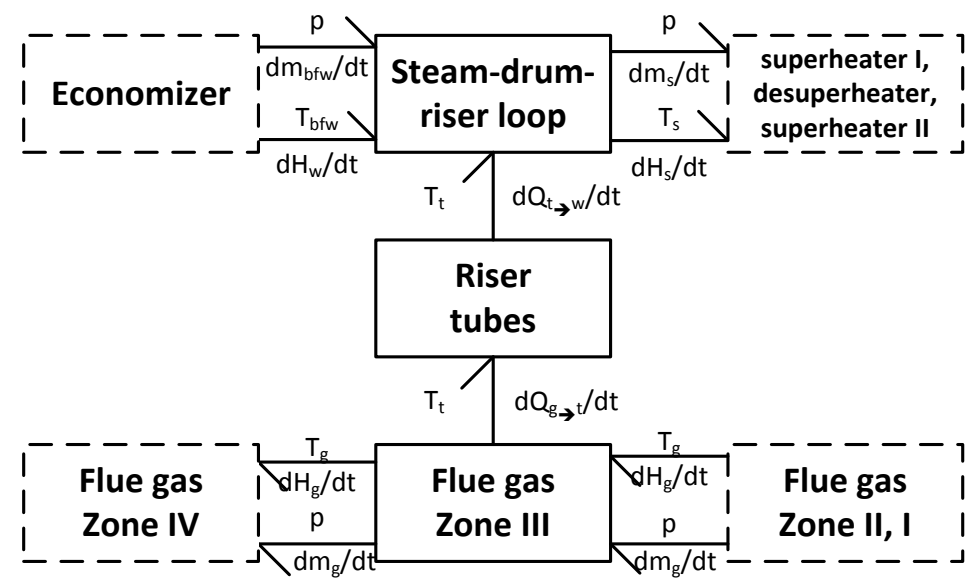

Figure 8 Details of word bond graph for steam-drum-riser loop subsystem.

In the mathematical model of the steam-drum-riser loop, the temperature and pressure of the steam-drum are denoted $\boldsymbol{y}_{\text {out }}$, while the $\boldsymbol{x}^{\prime} \boldsymbol{s}$ are temperature of steam drum, riser tubes and flue gas in the $3^{\text {rd }}$ zone. $\boldsymbol{u}^{\prime} \boldsymbol{s}$ denotes temperature and mass flow rate of boiler feed water and flue gas in the $3^{\text {rd }}$ zone, and $\boldsymbol{d}$ is the mass flow rate of the steam that is produced by the steam-drum.

\subsubsection{Word Bond Graph of Superheater I / II and Desuperheater}

The last three of the boiler subsystems considered in this paper, i.e. superheater I, the desuperheater, and superheater II are modeled in a word bond graph model. The ideal physical models are illustrated in Figure 9, while their bond graph model is depicted in Figure 10.

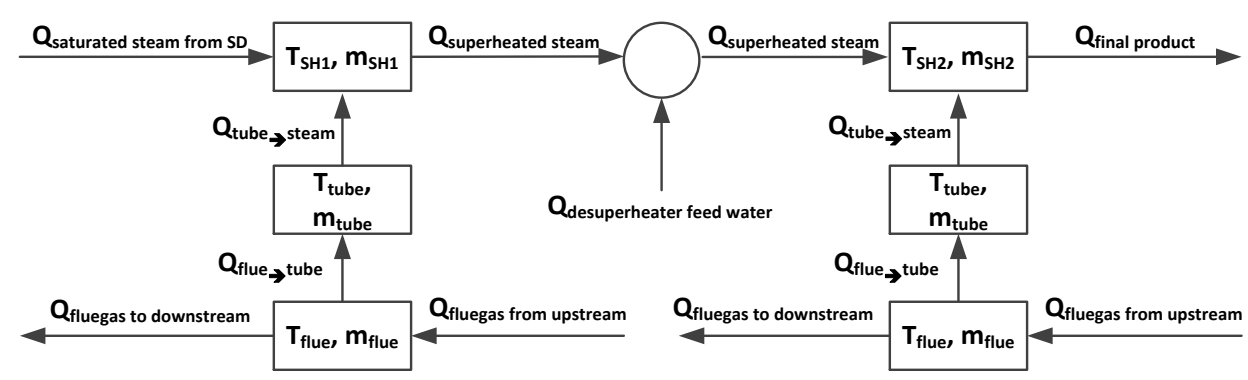

Figure 9 Ideal physical models of superheater I and II as well as desuperheater.

The output variables $\left(\boldsymbol{y}_{\text {out }}\right)$, state variables $(\boldsymbol{x})$, input variables $(\boldsymbol{u})$, and disturbance variables $(\boldsymbol{d})$, which are assigned as mathematical representations in the word bond graph model (Figure 10), are defined as follows. The 
temperatures of the superheater I and II output are set as output variables, while the temperature of the flue gas, the superheater tubes, and the steam at the superheaters and the desuperheater are assigned as state variables. The mass flow rate of the desuperheater feed water, steam input into superheaters, and combustion air supply are treated as input variables. The feed-water temperature of the desuperheater, as well as the mass flow rate of the steam output from superheater II are chosen as disturbance variables.

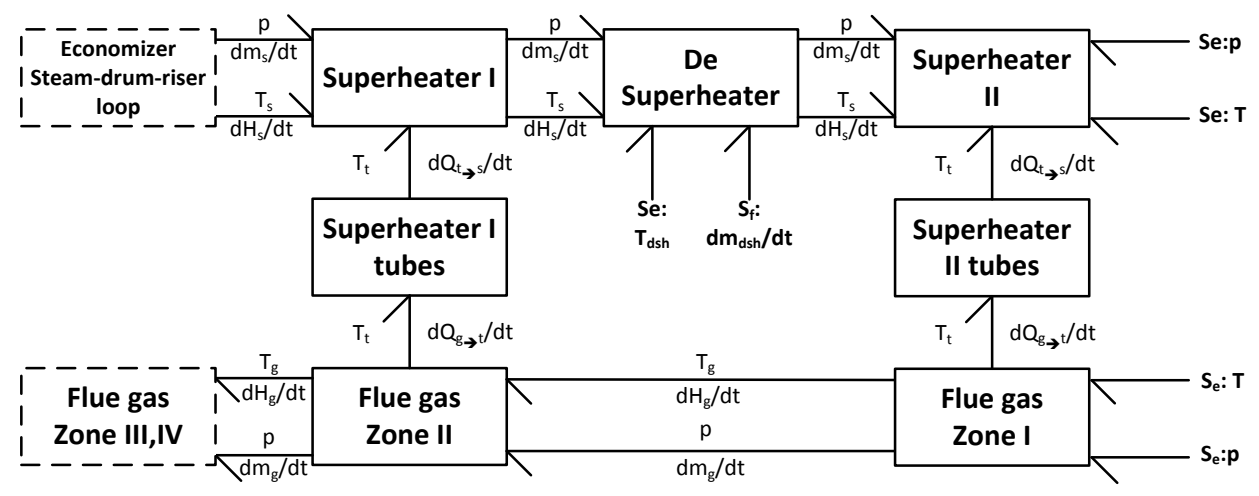

Figure 10 Detailed word bond graph of superheater I/II and desuperheater.

\subsection{Modeling Assumptions}

In order to derive a moderately complex model, the following assumptions were made. (1) Each subsystem is treated as a finite dimensional system, (2) their behaviors are not varied spatially, (3) the amount of accumulation of momentum energy balance is insignificant compared to the amount of heat energy balance, (4) the two phases of the water in the steam drum are in saturated condition, (5) the temperature dynamics of the steam drum metal are always in equilibrium with the steam temperature dynamics inside the steam drum, (6) the amount of water/steam accumulation inside the steam-drum-riser loop is determined only by the boiler feed water supply and steam produced.

\subsection{Bond Graph Model}

Energy transformation, dissipation, and accumulation are depicted by a bond graph model using pictorial diagrams. The main bond graph elements used in this article are: sources, flow storage, resistive, zero (0) junction and one (1) junction.

Thermal and hydraulic energy systems were used for modeling the heat transfer phenomena inside the industrial boiler. Temperature and pressure were choosen 
as effort variables, paired with enthalpy flow and mass flow rate as flow variables.

The bond graph model of the industrial boiler that agrees with Figure 4 is depicted in Figure 11 below. It consists of four types of energy systems, i.e. (1) hydraulic system of water cycle, (2) thermal system of water cycle, (3) thermal system of fire cycle, (4) hydraulic system of fire cycle. Each relevant element, such as the junctions, the energy dissipater as well as the energy storage, is numbered according to their type of energy system. The energy types are classified according to the first digit of the element's number. Any number with 1 as its first figure is categorized as hydraulic system of water cycle, 2 stands for thermal system of water cycle, 3 for thermal system of fire cycle, and 4 for hydraulic system of fire cycle.

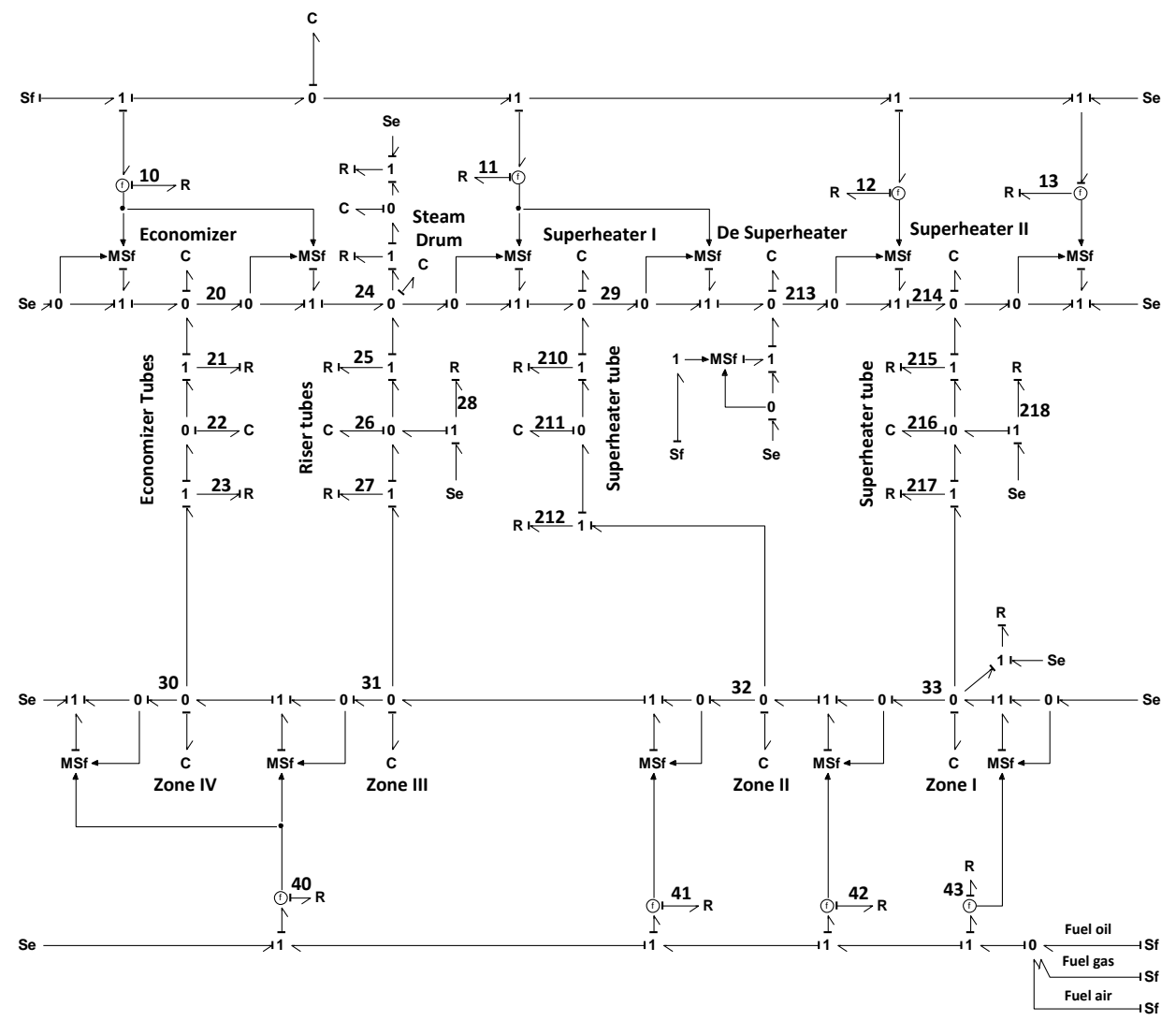

Figure 11 Bond graph model of industrial boiler.

The mathematical models of the industrial boiler are a combination of conservative and constitutive equations. Conservative equations consists of $\mathrm{C}$ 
elements and zero/one junctions, whereas constitutive equations are represented as $\mathrm{R}$ components. Conservative equations can be described by the following relations:

$$
\begin{aligned}
& e(t)=\frac{1}{C} \int f(s) d s, \text { or } \\
& f(t)=\frac{1}{L} \int e(s) d s .
\end{aligned}
$$

The letters $f$ and $e$ stand for the flow and effort variables. Eq. (2) defines the flow storage element, while Eq. (3) defines the effort storage element. $C$ and $L$ in the equations represent the capacity of the energy storage element. Their values depend on the design parameters of the subsystems. Constitutive equations of resistive elements generally take the following form:

$$
\begin{aligned}
& e(t)=R \mathcal{H}(f(t)), \text { or } \\
& f(t)=R^{-1} \mathcal{H}(e(t)) .
\end{aligned}
$$

$R$ is a resistance quantity that dependson the underlying physical phenomena. Zero and one junctions treat the flow and effort variables according to the following rule. At zero (0) junctions, the sum of all flows is zero and all efforts are equal (Eqs. (6)-(7)).

$$
\begin{aligned}
& f_{1}+f_{2}+\cdots+f_{n}=0 \\
& e_{1}=e_{2}=\cdots=e_{n}
\end{aligned}
$$

While at ones (1) junctions, sum of all efforts is zero and all flows are equal (Eqs. (8)-(9)).

$$
\begin{aligned}
& e_{1}+e_{2}+\cdots+e_{n}=0 \\
& f_{1}=f_{2}=\cdots=f_{n}
\end{aligned}
$$

An ordinary differential equation is directly obtained from the integral relation of Eqs. (2) and (3). If both equations are differentiated, the integral operators vanish, as indicated by Eqs. (10) and (11).

$$
\begin{aligned}
& \dot{e}(t)=\frac{1}{C} f(t) \\
& \dot{f}(t)=\frac{1}{L} f(t)
\end{aligned}
$$

More explanation about modeling physical systems using bond graph methodology can be found e.g. in Ljung and Glad [9]. 


\subsubsection{Mathematical Model of Economizer}

The mathematical model of the economizer comprises conservative and constitutive equations that are derived explicitly from Figure 11. The enthalpy storage is denoted as bond graph element C-20. This element computes the water temperature inside the economizer through the following relation:

$$
T_{20}=\frac{1}{C_{20}} \int\left(\dot{H}_{u}+\dot{Q}_{21}-\dot{H}_{d}\right) d t
$$

$\dot{H}_{u}$ and $\dot{H}_{d}$ can be calculated using Eqs. (13)-(14). As a note, $h_{w, T_{b f w}}$ is a function of $T_{b f w}$ and $h_{w, T_{20}}$ is a function of $h_{w, T_{20}}$.

$$
\begin{aligned}
& \dot{H}_{u}=\dot{m}_{b f w} \times h_{w, T}{ }_{b f w} \\
& \dot{H}_{d}=\dot{m}_{b f w} \times h_{w, T_{20}}
\end{aligned}
$$

$C_{20}$ is computed from Eq. (15). $c_{w}, T_{20}$ and $\rho_{w, T_{20}}$ depend on $T_{20}$.

$$
C_{20}=V_{e c o} \times \rho_{w, T_{20}} \times c_{w, T_{20}}
$$

$\dot{Q}_{21}$ is the amount of heat transferred from the economizer tube to the boiler feed water by a convective mechanism. The relation is described by Eq. (16):

$$
\dot{Q}_{21}=h_{\text {tube } \rightarrow b f w} \times A_{\text {eco }}\left(T_{22}-T_{20}\right) .
$$

The tube's temperature is evaluated using Eqs. (17)-(22):

$$
\begin{aligned}
& T_{22}=\frac{1}{C_{22}} \int\left(\dot{Q}_{23}-\dot{Q}_{21}\right) d t, \\
& C_{22}=V_{\text {tube }} \times \rho_{\text {tube }} \times c_{\text {tube }}, \\
& \dot{Q}_{23}=h_{g a s} \rightarrow \text { tube } \\
& T_{30}=\frac{1}{C_{30}} \int\left(\dot{m}_{g 4} h_{g, T_{31}}-\dot{Q}_{30}-T_{22}\right), \\
& C_{30}=\dot{m}_{g 4} h_{g, T_{30}} \times \rho_{g 4, T_{30}} \times c_{g 4, T_{30}}, \text { and } \\
& \dot{m}_{g 4}=\left(R_{40}\left(p_{40}-p_{0}\right)\right)^{0,5} .
\end{aligned}
$$

The term in Eqs. (20)-(21) indicates that their values depend on $T_{x x} . R_{40}$ is a constant, while Eq. (22) is a constitutive equation derived from the continuity equation. 


\subsubsection{Mathematical Model of Steam-Drum-Riser Loop}

Similar to those of the economizer, the mathematical models of the steam-drumriser loop can be derived almost directly from Figure 11. The following equations are self-explanatory.

The temperature dynamic of the steam-drum-riser loop is:

$$
T_{24}=\frac{1}{C_{24}} \int\left(\dot{m}_{b f w} h_{w, T_{b f w}}+\dot{Q}_{25}-\dot{m}_{\text {steam }} h_{s, T_{24}}\right) d t .
$$

The heat capacity, $C_{24}$ is computed as follows:

$C_{24}=h_{w, T_{24}} V_{w} \frac{\partial \rho_{w, T} 24}{\partial T}+\rho_{w, T_{24}} V_{w} \frac{\partial h_{w, T} 24}{\partial T}+h_{s, T_{24}} V_{s} \frac{\partial \rho_{s, T}, 4}{\partial T}+\rho_{s, T_{24}} V_{s} \frac{\partial h_{s, T}}{\partial T}-$

$V_{\text {tot }} \frac{\partial p_{24, T} T_{24}}{\partial T}+m_{m} c_{m}$.

The steam drum pressure is interpolated from the steam table:

$$
p_{25}=\mathcal{F}\left(T_{24}\right) \text {. }
$$

The water volume is computed by:

$$
V_{w}=V_{t o t}-V_{s}
$$

The mass flow rate of the steam product is:

$$
\dot{m}_{\text {steam }}=\left(R_{11}\left(p_{24}-p_{\text {header }}\right)\right)^{0,5} .
$$

The heat flow from the tube to the fluid due to a convection mechanism is:

$$
\dot{Q}_{25}=h_{\text {tube } \rightarrow \text { water }} \times A_{\text {riser }}\left(T_{26}-T_{24}\right) .
$$

The temperature dynamic of the boiler bank tubes is computed by:

$$
\begin{aligned}
& T_{26}=\frac{1}{C_{26}} \int\left(\alpha_{1} \dot{Q}_{27}+\left(1-\alpha_{1}\right) \dot{Q}_{28}-\dot{Q}_{25}\right) d t, \\
& C_{26}=V_{\text {tube }} \times \rho_{\text {tube }} \times c_{\text {tube }}, \\
& \dot{Q}_{27}=h_{\text {gas } \rightarrow \text { tube }} \times A_{\text {riser }}\left(T_{31}-T_{26}\right), \\
& \dot{Q}_{28}=F \times \sigma \times A_{\text {riser }}\left(T_{31}^{4}-T_{26}^{4}\right), \\
& T_{31}=\frac{1}{C_{31}} \int\left(\dot{m}_{g 3} h_{g 3, T_{32}}-\dot{Q}_{27}-\dot{m}_{g 3} h_{g 3, T_{31}}\right) d t,
\end{aligned}
$$




$$
\begin{aligned}
& C_{31}=V_{g 3} \times \rho_{g 3, T_{31}} \times c_{g 3, T_{31}}, \text { and } \\
& \dot{m}_{g 3}=\left(R_{41}\left(p_{41}-p_{40}\right)\right)^{0,5} .
\end{aligned}
$$

$\alpha_{1}$ is a constant between $0-1$ that suggests there is a linear combination of heat transferred from the flue gas to the riser tube due to a radiation and convection mechanism. $F$ is a constant relating to configuration between object and source of radiation

\subsubsection{Mathematical Model of Superheater I}

The mathematical model of superheater I is expressed in Eqs. (36)-(45). Eq. (36) describes the temperature dynamics of superheater I.

$$
T_{29}=\frac{1}{C_{29}} \int\left(\dot{m}_{\text {steam }} h_{s, T_{24}}+\dot{Q}_{210}-\dot{m}_{\text {steam }} h_{s, T_{29}}\right) d t,
$$

where

$$
\dot{m}_{\text {steam }}=\left(R_{11}\left(p_{24}-p_{\text {header }}\right)\right)^{0,5} .
$$

The heat capacity of the fluid inside the superheater I tube is:

$$
C_{29}=V_{S H 1} \times \rho_{s, T_{29}} \times c_{S, T_{29}} .
$$

The heat flow from tube to steam is:

$$
\dot{Q}_{210}=h_{\text {tube } \rightarrow \text { steam }} \times A_{S H 1} \times\left(T_{211}-T_{29}\right) .
$$

The temperature dynamic in the superheater I tube is:

$$
\begin{aligned}
& T_{211}=\frac{1}{C_{211}} \int\left(\dot{Q}_{212}-\dot{Q}_{210}\right) d t, \\
& C_{211}=V_{\text {tube }} \times \rho_{\text {tube }} \times c_{\text {tube }}, \\
& \dot{Q}_{212}=h_{\text {gas } \rightarrow \text { tube }} \times A_{S H 1} \times\left(T_{32}-T_{211}\right), \\
& T_{32}=\frac{1}{C_{32}} \int\left(\dot{m}_{g 2} h_{g, T_{33}}-\dot{Q}_{212}-\dot{m}_{g 2} h_{g, T_{32}}\right) d t, \\
& C_{32}=V_{g 2} \times \rho_{g, T_{32}} \times c_{g, T_{32}}, \text { and } \\
& \dot{m}_{g 2}=\left(R_{42}\left(p_{42}-p_{41}\right)\right)^{0,5} .
\end{aligned}
$$




\subsubsection{Mathematical Model of Desuperheater}

The proposed mathematical model of the desuperheater is expressed in Eqs. (46)-(48).

$$
\begin{aligned}
& T_{213}=\frac{1}{C_{213}} \int\left(\dot{m}_{S H 1} h_{s, T_{29}}+\dot{m}_{d s h} h_{s, T_{d s h}}-\left(\dot{m}_{S H 1}+\dot{m}_{d s h}\right) h_{s, T_{213}}\right) d t \\
& C_{213}=\left(\dot{m}_{S H 1}+\dot{m}_{d s h}\right) \times c_{s, T_{213}}, \text { and } \\
& \dot{m}_{S H 1}=\dot{m}_{\text {steam }} .
\end{aligned}
$$

The dimension of the desuperheater is small enough compared to that of superheater I and II, so Eqs. (46) and (47) approach its condition by using the mass flow rate of the steam and the desuperheater feed water multiplied by the specific heat capacity of the steam at a given temperature as thermal energy storage. This approach differs from the equation suggested by Maffezoni [10] as follows:

$$
\dot{T}_{\text {out }}=\frac{1}{C_{P}} \Delta h_{\text {out }}=\frac{\bar{h}_{\text {in }}-\bar{h}_{\text {out }}}{C_{p} \bar{m}_{\text {out }}} \dot{m}_{\text {out }}+\frac{\bar{m}_{\text {in }}}{\bar{m}_{\text {out }}} \dot{T}_{\text {in }}-\frac{\bar{h}_{\text {in }}-\bar{h}_{\text {spray }}}{C_{p} \bar{m}_{\text {out }}} \dot{m}_{\text {spray }} .
$$

The variable $\dot{m}_{\text {out }}$ is calculated using:

$$
\dot{m}_{\text {in }}+\dot{m}_{\text {spray }}=\dot{m}_{\text {out }} .
$$

It can be noted that Eqs. (46)-(48) is more straightforward than that of Maffezoni's.

\subsubsection{Mathematical Model of Superheater II}

The steam temperature going out of superheater II as well as the thermal capacity calculation are expressed by Eqs. (49)-(61):

$$
\begin{aligned}
& T_{214}=\frac{1}{C_{214}} \int\left(\dot{m}_{S H 1} h_{S, T_{213}}+\dot{Q}_{215}-\dot{m}_{S H 2} h_{S, T_{214}}\right) d t, \\
& C_{214}=V_{S H 2} \times \rho_{s, T_{214}} \times c_{s, T_{214}}, \text { and } \\
& \dot{m}_{S H 2}=\dot{m}_{S H 1}=\dot{m}_{\text {steam }} .
\end{aligned}
$$

The heat transferred from tube to steam:

$$
\dot{Q}_{215}=h_{\text {tube } \rightarrow \text { steam }} \times A_{S H 2} \times\left(T_{216}-T_{214}\right) .
$$


The temperature dynamic of the superheater tube due to a convection and radiation heat transfer mechanism is expressed by Eqs. (53)-(61):

$$
\begin{aligned}
& T_{216}=\frac{1}{C_{216}} \int\left(\alpha_{2} \dot{Q}_{217}+\left(1-\alpha_{2}\right) \dot{Q}_{218}-\dot{Q}_{215}\right) d t, \\
& \dot{Q}_{217}=h_{g a s} \rightarrow \text { tube } \\
& \dot{Q}_{218}=F \times A_{S H 2} \times\left(T_{33}-T_{216}\right), \\
& T_{33}=\frac{1}{C_{33}} \int\left(\dot{m}_{g 1} h_{g, T_{\text {combustion }}}-\dot{m}_{g 1} h_{g, T_{33}}-\dot{Q}_{217}\right) d t, \\
& C_{33}=V_{g 1} \times \rho_{g, T_{33}} \times c_{g, T_{33}}, \text { and } \\
& \dot{m}_{g 1}=\left(R_{43}\left(p_{43}-p_{42}\right)\right)^{0,5} .
\end{aligned}
$$

The combustion enthalpy, $h_{g, T_{\text {combustion }}}$, is computed by the following equations:

$$
\begin{aligned}
& \dot{m}_{\text {gas }}=\dot{m}_{\text {fuel }}+\dot{m}_{\text {air }}, \\
& \dot{Q}_{\text {combustion }}=\dot{m}_{\text {fuel }} h_{\text {fuel }}+\dot{m}_{\text {air }} h_{\text {air }}, \text { and } \\
& h_{g, T_{\text {combustion }}}=\frac{\dot{Q}_{\text {combustion }}}{\dot{m}_{\text {gas }}} .
\end{aligned}
$$

\subsection{Model Summary}

The above equations can be arranged into a general form $\boldsymbol{y}=\mathcal{F}(\boldsymbol{x})$, and $\dot{x}=\mathcal{G}(\boldsymbol{x}, \boldsymbol{u}, \boldsymbol{d})$, where $\boldsymbol{y}$ is output variable vector, $\boldsymbol{x}$ is state variable vector, $\boldsymbol{u}$ is input variable vector, and $\boldsymbol{d}$ is disturbance variable vector. The elements of $\boldsymbol{y}$ are temperature of: economizer, economizer's tube, $4^{\text {th }}$ zone, steam drum, riser tubes, $3^{\text {rd }}$ zone, superheater I, superheater I's tube, $2^{\text {nd }}$ zone, output of desuperheater, superheater II, superheater II's tube, and $1^{\text {st }}$ zone, or

$$
\boldsymbol{y}=\left[T_{20}, T_{22}, T_{30}, T_{24}, T_{26}, T_{31}, T_{29}, T_{211}, T_{32}, T_{213}, T_{214}, T_{216}\right]
$$

The elements of are similar to or,

$$
\boldsymbol{x}=\left[T_{20}, T_{22}, T_{30}, T_{24}, T_{26}, T_{31}, T_{29}, T_{211}, T_{32}, T_{213}, T_{214}, T_{216}\right]
$$

The elements of are mass flow rate of fuel, combustion air supply, boiler feed water and desuperheater feed water, which are:

$$
\boldsymbol{u}=\left[\dot{m}_{f u e l}, \dot{m}_{\text {air }}, \dot{m}_{b f w}, \dot{m}_{d s h}\right]
$$


The elements of are steam pressure at the steam header, or

$$
\boldsymbol{d}=\left[p_{\text {header }}\right]
$$

\subsection{Properties of Fluid and Metal}

The properties of specific enthalpy, specific mass, and specific heat of water, steam, and gas are interpolated from the steam table. They are calculated using the MATLAB function provided by Holmgreen [11]. The properties of the steam under superheated conditions and the flue gas properties are estimated using Tables 1, 2, 3, and 8(b) in [12]. The specific heat of the metal is found elsewhere in Flenner [13]. The heat transfer coefficients of the boiler tubes are estimated from boiler performance test data using a genetic algorithm (GA). The application of GA's for boiler model improvement is elaborated e.g. in Aziz, et al. [14]. Proper adjustments were performed for two constants, i.e. $\alpha_{1}$ and $\alpha_{2}$, according to the heat transfer mechanism in the $3^{\text {rd }}$ and $4^{\text {th }}$ flue gas zone. Bond graph resistive elements were determined through the steady state relationships of specific equations using performance test data.

\section{$4 \quad$ Result and Discussion}

In the previous sections, a mathematical model derivation of boiler subsystems using bond graph methodology has been elaborated. Although it looks complicated, the method offers modeling activity of a complex system in a straightforward and systematic way. For example, it can be compared to other boiler models developed by Astrom and Bell [2] or Maffezoni [10]. Astrom and Bell utilized mass end energy balance to analytically derive temperature and pressure dynamic equations in the steam-drum of a water tube boiler. Tedious efforts have been made to produce a mathematical model of a steam drum that is consistent with the state equation form. Unlike the bond graph methodology, Astrom and Bell's models does not clearly state which equation is influenced by which energy system. The energy coupling phenomena in Astrom and Bell's model is intrinsically treated during analytical derivation. Comparison of Maffezoni's desuperheater model derivation with the derivation of Eq. (46) using the bond graph method gives another example of how promising the proposed method is for structuring the modeling activity of a complex system. Furthermore, the procedures of structuring such a complex system into word bond graph and bond graph models have directly classified design parameters, thermodynamic parameters, and hydrodynamic parameters. This feature will help advancing the utilization of the resulted model as a tool for designing, evaluating, and optimizing boiler performance. Last but not least, by using the bond graph methodology, there is no need to start modeling from the beginning 
if it is necessary to increase the complexity and resolution of the model. The previous model can be combined with newer or more detailed ones.

\subsection{Simulation}

As a tool for model performance evaluation, a boiler simulator based on the MATLAB/Simulink program has been made. As a graphical based programming language, Simulink is a suitable tool to simulate bond graph models. Each bond graph element can be coded into the Simulink graphical language almost as it is. The simulator provides an important means to other works, like parameter estimation using a GA. It can also be used to evaluate physical assumptions, empirical equations, and model performance. The simulator can also serve as a boiler plant when there is a need to examine a new control algorithm, but it is impossible to access the real boiler.

The output temperature of the economizer, steam drum, superheaters, and desuperheater were examined through the simulator. The parameters of the simulations were taken from a performance test and design data of the industrial boiler. The simulation was performed separately for economizer, steam drum, and superheater. These different kinds of simulation were carried out for different boiler loads, i.e. $110 \%, 90 \%$, and $50 \%$. The relevant boiler performance test data are listed in Table 1 below.

Table 1 Boiler performance test data.

\begin{tabular}{llll}
\hline Performance data & I & II & III \\
\hline Steam load, $\%$ & 110 & 90 & 50 \\
BFW, kg/hr & 127368 & 115789 & 57895 \\
Gas temperature, ${ }^{\circ} \mathrm{C}$ & & & \\
Economizer in & 340 & 333 & 301 \\
Economizer out & 188 & 185 & 172 \\
Superheater in & 1030 & 1000 & 830 \\
Boiler bank in & 820 & 800 & 640 \\
Water $/$ steam temperature & & & \\
Eco. in, ${ }^{\circ} \mathrm{C}$ & 160 & 160 & 160 \\
Eco. out, ${ }^{\circ} \mathrm{C}$ & 208 & 206 & 201 \\
Steam drum, ${ }^{\circ} \mathrm{C}$ & 286 & 284 & 279 \\
SH out, ${ }^{\circ} \mathrm{C}$ & 371 & 369 & 357 \\
\hline Note: Cont. $=$ continuous, BD $=$ blow-down, $\mathrm{BFW}=$ boiler feed- \\
water, SH = superheater, Eco = economizer.
\end{tabular}

The simulation was done using the following inputs: a fuel flow rate of $8400 \mathrm{~kg} / \mathrm{hr}$ (with high-heating value of $12553 \mathrm{kkal} / \mathrm{kg}$ ), a boiler feed-water flow rate of $127368 \mathrm{~kg} / \mathrm{hr}$, a boiler desuperheater feed-water flow rate of $6368 \mathrm{~kg} / \mathrm{hr}$, and an air to fuel ratio of $15 \%$. The initial conditions of the simulation were 
defined as follows: temperature of boiler feedwater inlet $=160^{\circ} \mathrm{C}$, temperature of desuperheater feedwater $=50^{\circ} \mathrm{C}$, temperature of economizer $=160^{\circ} \mathrm{C}$, temperature of steam drum $=280$, temperature of superheater $\mathrm{I}=400^{\circ} \mathrm{C}$, temperature of superheater II $=300$, and steam-header pressure $=65 \mathrm{~kg} / \mathrm{cm}^{2}$.

Figure 12 demonstrates the simulation results of the temperature state for the economizer and the superheater subsystem of the steam drum. It can be noted that the trend of each graph confirms the underlying physical phenomena. There are increases in temperature and pressure as a response to the energy they absorbed. The time for each part to reach its steady temperature varies depending on control volume, steam load, and amount of heat absorbed. The bigger the control volume is, the longer it takes to reach steady state condition. It also reveals that the operating temperatures vary with respect to the steam load. Figure 13 depicts the temperature dynamics in the boiler tubes and boiler zones.

However, discrepancies are found between the boiler simulation results and the performance test data. The biggest deviations are displayed by the superheater model. These are possibly due to unmodeled dynamics that are not captured by the proposed equations. For example, the models are considered as a lumped model, while the real objects may have a more complex model. To overcome such difficulties, some unknown parameters can be added to capture the unmodeled dynamics. Subsequently, some optimization procedures are employed to search their values. Yet, these methods need more or less adequate experimental data for model estimation and validation, which were not available at this time.
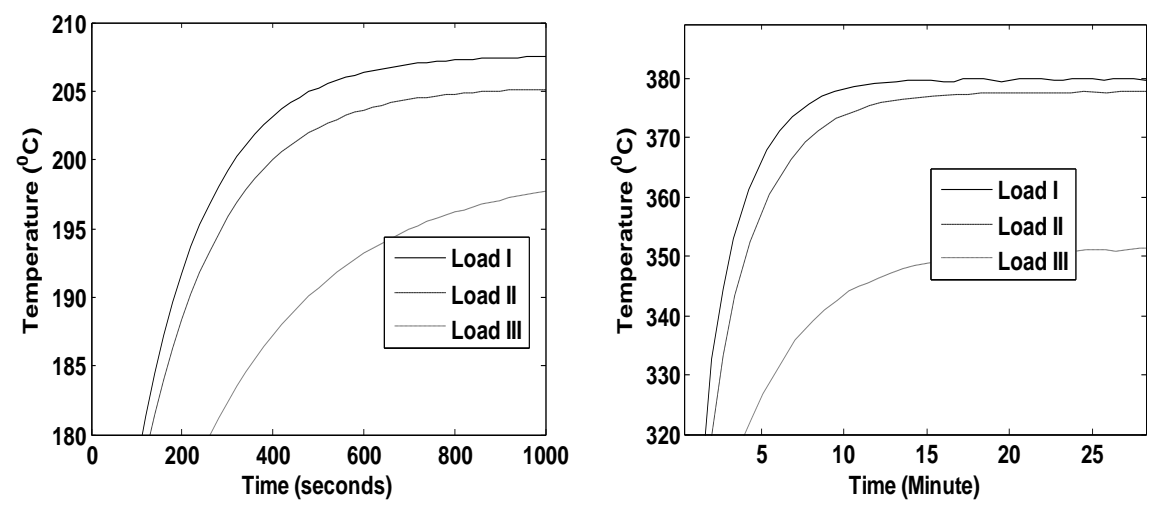

Figure 12 (a) Temperature dynamics of economizer, (b) Temperature dynamics of superheater. 

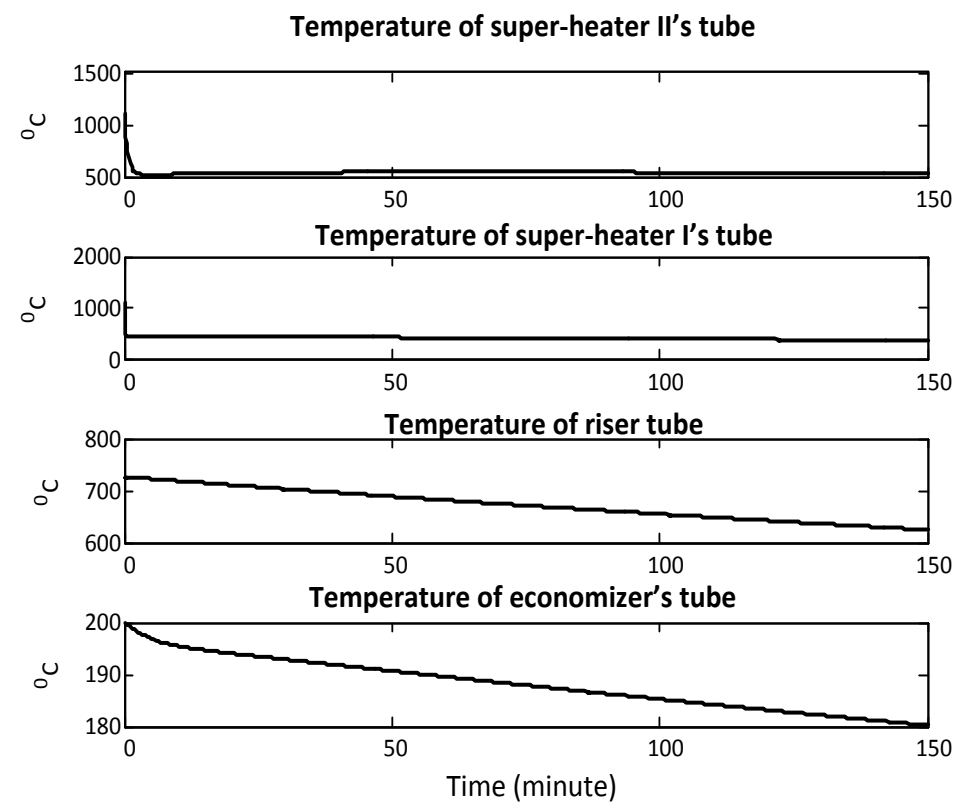

Figure 13 Temperature dynamic of boiler tubes during step input change.

\section{Conclusion}

This paper presented a methodology for modeling the temperature and pressure behavior of an industrial boiler using mathematical equations guided by the bond graph technique. The mathematical models, based on ordinary differential and algebraic equations were obtained from the procedure. The solutions of the equations were found in the MATLAB/Simulink environment. The Simulink models are structured similar to those of the bond graph model and the solutions are performed using numerical integration sub-routines provided in the software. The potential of the proposed model to capture the dynamical properties of an industrial boiler were shown from a comparison of the simulation results with steady state performance test data. Actually, the derived model only dealt with the water/steam cycles. They absorb heat from hightemperature flue gas, which is a combustion product. Among several main flue gas properties are temperature, pressure, and mass flow rate. A limitation of the model is the absence of a dynamic mathematical model that describes the flue gas properties. In order to build such a model, adequate data from the boiler chamber and combustion reactions should be available. The absence of a combustion model was temporarily solved using interpolation of a flue gas table, although this only served as a steady state solution. 


\section{Acknowledgements}

The research was facilitated by the Institute for Research and Community Services, Bandung Institute of Technology under the Research Group scheme. The authors would like to express their sincere thankfulness for this support. There was also significant assistance from PT. Pertamina Cilacap Refinery Plant, Indonesia in providing the boiler design and performance test data. This help was very much appreciated.

\section{Nomenclature}
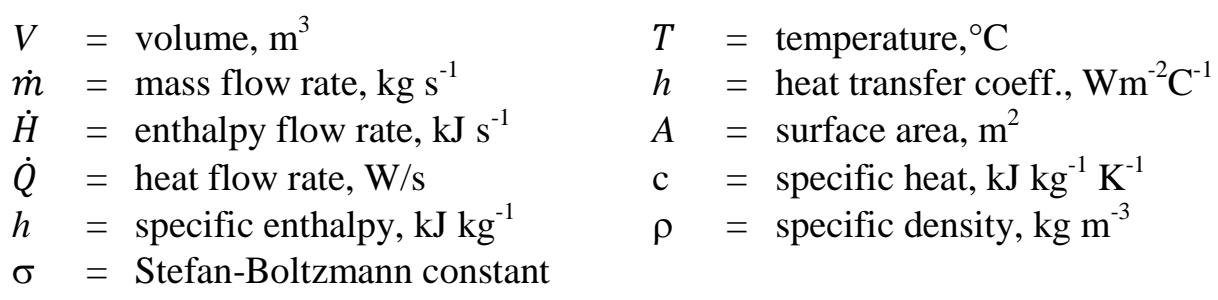

Subscripts:

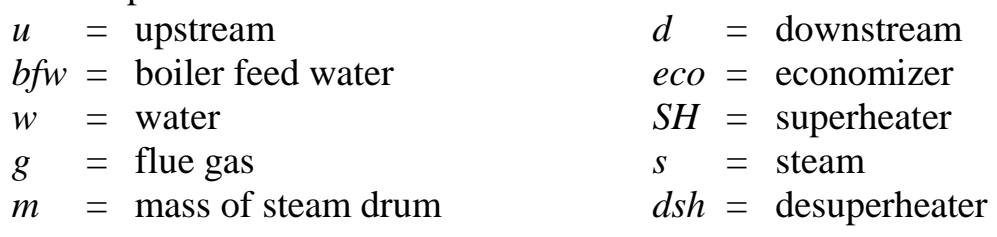

\section{References}

[1] Abdulmoneim, M.M., Aboelela, M.A.S. \& Hassen T. Dorrah, Hybrid Modeling of Power Plant and Controlling Using Fuzzy P+ID with Application, International Journal of Advances in Engineering \& Technology, 4(1), pp. 42-53, 2012.

[2] Astrom, K.J. \& Bell, R., Drum Boiler Dynamics, Automatica, 36, pp. 362-378, 2000.

[3] Cheres, E., Small and Medium Size Drum Boiler Models Suitable for Long Term Dynamic Response, IEEE Transactions on Energy Conversion, 5(4), pp 686-692, 1990.

[4] Mello, F.P.de, Boiler Models for System Dynamic Performance Studies, IEEE Transactions on Power Systems, 6(1), pp. 753-761, 1991.

[5] Nazaruddin, Y.Y., Aziz, N.A. \& Sudibjo, W., Improving the Performance of Industrial Boiler Using Artificial Neural Network Modeling and Advanced Combustion Control, Int. Conf. on Control, Automation and Systems 2008, Oct. 14-17, in COEX Seoul, Korea, 2008.

[6] Nazaruddin, Y.Y., Aziz, N.A. \& Prijatna, O., Improving Performance of PID Controller Using Artificial Neural Network for Disturbance 
Rejection of High Pressure Steam Temperature Control in Industrial Boiler, Int. Conf. on Control, Automation and Systems 2008, in COEX Seoul, Korea, 2008.

[7] Boroutzky, W., Bond Graph Methodology, London: Springer-Verlag, 2010.

[8] Medjaher, K., Samantaray, A.K. \& Ould Bouamama, B., Bond Graph Model of A Vertical U-Tube Steam Condenser Coupled with a Heat Exchanger, Simulation Modeling Practice and Theory, 17, pp. 228-239, 2009.

[9] Ljung, L. \& Glad, T., Modeling of Dynamics System, Prentice-Hall, p. 120, 1994.

[10] Maffezoni, C., Boiler-Turbine Dynamics in Power Plant Control, Control Engineering Practice, 5(3), pp. 301-312, 1997.

[11] Holmgreen, M., XSTEAM for MATLAB 2006, http://www.x-eng.com (30 October 2009).

[12] The Babcox and Wilcox Company, Steam, Its Generation and Use, $41^{s t}$ edition, pp. 2-4, 2-5, Kitto, J.B. \& Stultz, S.C., eds., Ohio, United States, 2005.

[13] Flenner, P., Carbon Steel Handbook, EPRI, Palo Alto, CA: 1014670, 2007.

[14] Aziz, A.N., Siregar, P., Nazaruddin, Y.Y. \& Bindar, Y., Improving the Performance of Temperature Model of Economizer Using Bond Graph and Genetic Algorithm, International Journal of Engineering and Technology, 12(1), 2012. 